\title{
Measuring the Technical Efficiency of Decision Making Units by CCR Model in Data Envelopment Analysis
}

\author{
Raju Nellutla $^{1^{*}}$, M. Goverdhan ${ }^{2}$, V.V. Haragopal ${ }^{3}$ \\ ${ }^{1}$ Department of Mathematics, Guru Nanak Institutions Technical Campus, Hyderabad, Telangana ,India. \\ ${ }^{2}$ Department of Mathematics, C V R College of Engineering, Hyderabad, Telangana ,India. \\ ${ }^{3}$ Department of Mathematics, Birla Institute of Technology and Science, Pilani- Hyderabad Campus, Telangana ,India . \\ *Corresponding Author: rajunellutla@gmail.com, Tel.: +91-98495-86081
}

Available online at: www.isroset.org

Accepted 20/Aug/2018, Online 30/Aug/2018

\begin{abstract}
In this paper we analyse the Board of Intermediate Public Examination (IPE) data by CCR model in Data Envelopment Analysis for the Andhra Pradesh state district wise. To see the Technical efficiency Performance of the districts in Andhra Pradesh state prior to the division of state. The Performance of the districts is presented along with the Peer, Reference set, potential improvements and Technical efficiency Performance of the state by CCR Model in Data Envelopment Analysis and also based on the reference set and peer weight, we can express the input and output values of in efficient districts needed to bring in to efficient status.
\end{abstract}

Keywords - CCR Model, Data Envelopment Analysis, Performance, Peers, Potential Improvement, Technical Efficiency.

\section{INTRODUCTION}

For decades, many applied fields share common concern over design and action on how to improve the data analytics. The concept of best practices is to deliberate action in Private and Government sectors for improvement. There are three important characteristics associated with a "best practice": a comparative process, an action and link between an action and some out comes or goals. From 1980's on wards, researchers started to direct their efforts towards extending "best practice" to Education sector. This led to school improvement initiatives and studies on the characteristics of School Environment conductive to learning [1]. In various parts of the world researchers like Rhodes, Cooper and Thanassoulis started seeking appropriate measurement methodologies for school efficiency. Rodhes and Southwick studied about the efficiency in U.S.A. Private Universities in comparison to the Public Universities, by applying Data Envelopment Analysis model and they regarded as decision making units on the university as whole and analysed the data.

Kwimbere [2] applied DEA model to assess the performance of Decision Making Units viz., Engineering, Mathematics and Physics departments of a set of universities in U.K and [3] assessed the Performance of Management Schools in Secondary School Examinations of Andhra Pradesh State for academic years 2009-10 and 2010-11 by Data Envelopment Analysis.In this study we analyse the
Board of Secondary Education (BSE) in Andhra Pradesh to assess which district fares well for the data collected for the academic year 2012-14 by CCR in Data Envelopment Analysis.

\section{Data EnVelpment Analysis}

Data Envelopment Analysis is relatively "data oriented" approach for evaluating the performance of a set of peer entities called decision making entities, which convert multiple inputs in to multiple outputs.In the recent years, the DEA has emerged in to a greater variety of application for using evaluating the performance of many different kinds of entities engaged in many different activities in many different contexts in many different countries world over.DEA represents a great progression of continuous advancing for the data analysis, which find extensive use in industry, society and even in Education.[4] performed a critical Data Envelopment Analysis of hospital efficiency in India and found interesting results in health care issues.

In this study we consider Data Envelopment analysis (DEA) is used in an attempt to deal with the issue of measuring the Technical efficiency of the districts in Andhra Pradesh. The technique DEA was employed for the multiple inputs and outputs for evaluating the summary measure of efficiency of the data. This evaluation can be conducted not only at the organization level but also in sub units such as 
number of boys and girls appeared in examination in district wise and their results. [5] assessed the Technical efficiency of Management Schools in Secondary School Examinations of Andhra Pradesh by CCR model.

2.1 Educational inputs: The resources or input indicators are units of measurement, which represent the factors used to carry out the delivery of services. Identification and measurement of these factors is crucial in a fair evaluation of the economy and efficiency in the programs and services management. Previous studies on other performance models [6] have shown that inputs of universities can be categorized in various ways. Here Educational Inputs are district wise number of boys and girls appeared in Public Examination.

2.2 Educational Outputs: Output indicators measure the level of activity of programs and services. Furthermore, it is always useful to disclose indicators that provide information about the quantity and the quality of the activity [7]. The quality, as an attribute that affects the user's perception, can also modify the productive process input/output relation. For this reason, it must be considered to access the efficiency of the process. Authors [8] Constructed DEA methodology to measure risk of commercial Banks. Raju Nellutla [9] Constructed Data Envelopment Analysis to know the Performance of the districts in SSC Public Examinations for the years 2009 - 2011 of Andhra Pradesh. In our case we give the Educational outputs of the Public Examination is number boy and girls passed out in public Examination in district wise.

\section{EFFICIENCY}

The efficiency analysis is always computed to assess the performance of an organization. The Efficiency is an important factor in economic analysis, where the process has a single input and single output, then efficiency is defined as :

$$
\text { Efficency }=\frac{\text { Output }}{\text { Input }}
$$

the theory of production from the economic point of view then can be considered as a formal model to link inputs and outputs, This theory has several strengths. First, some formal relationship between inputs and outputs exists and a “ best practice " can be identified by comparing different units transforming in to inputs to output where all units are assessed relative to that of optimum. The production process that occurs in educational institutions seem to have the same characteristics of the above economic model in the business sector- utilization of physical and human resources as inputs to compute outputs as shown in below.

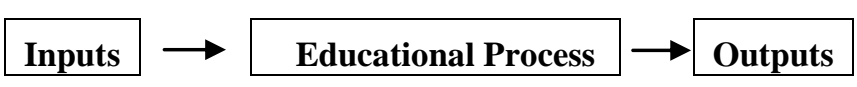

\section{Figure 1 Transformation Input/ Output Process}

3.1 The CCR Model: In Data Envelopment Analysis (DEA) the most widely used model is CCR Model [10] and [11] . A Constant Return to Scale relationship is assumed between Inputs and Outputs. It was the first Data Envelopment Analysis model to be developed CCR after Charnes, Cooper and Rhodes who introduced this. This model calculates the Overall Efficiency (OE) for each unit, Where the both Technical Efficiency and Scale Efficiency are aggregated in to one value. The Primal CCR model is explained as follows:

Decision Making Units $\mathrm{DMU}_{\mathrm{j}}$ : The $\mathrm{j}^{\text {th }}$ Decision Making Unit $\mathrm{j}=1,2,3, \ldots, \mathrm{n}$

$\boldsymbol{x}_{\boldsymbol{i} j}$ : The amount of the $\mathrm{i}^{\mathrm{th}}$ input of the $\mathrm{j}^{\text {th }}$ Decision making Units $\mathrm{x}_{1 \mathrm{j}}, \mathrm{x}_{2 \mathrm{j}}, \mathrm{x}_{3 \mathrm{j}}, \ldots, \mathrm{x}_{\mathrm{nj}}$

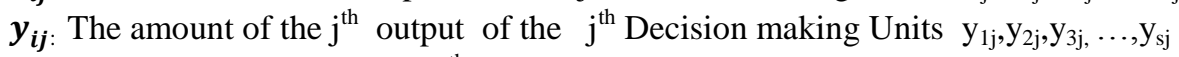

$v_{i}$ : The weight assigned to the $i^{\text {th }}$ input $\quad, i=1,23, \ldots, n$.

$\boldsymbol{u}_{\boldsymbol{r}}$ : The weight assigned to the $\mathrm{r}^{\text {th }}$ output , $\mathrm{r}=1,23, \ldots, \mathrm{s}$.

The Fractional Programming Problem ( FPP) is :

Maximize $R=\frac{u_{1} y_{1 k}+u_{2} y_{2 k}+\cdots+u_{s} y_{s k}}{v_{1} x_{1 k}+v_{2} x_{2 k}+\cdots+v_{m} x_{m k}}$

Subject to constraints: $\frac{u_{1} y_{1 j}+u_{2} y_{2 j}+\cdots+u_{s} y_{s j}}{v_{1} x_{1 j}+v_{2} x_{2 j}+\cdots+v_{m} x_{m j}} \leq 1, \quad \mathbf{j}=1,2, \ldots, \mathbf{n}$

and non negativity

$$
u_{1}, u_{2}, u_{3}, \ldots, u_{s} \geq 0, v_{1}, v_{2}, v_{3}, \ldots v_{m} \geq 0
$$

The ratio of input and output should not exceed 1 for every decision making unit. The objective is to Maximize the decision making units. The optimal value of $\mathrm{R}^{*}$ is at most one. Mathematically, non negativity constraints (4) is not sufficient for the fractional terms in (3) to have a positive value. Now we replace the Factional Program (FP) by the following Linear Programming Problem (LPP),

Maximize $R(u, v)=u_{1} y_{1 k}+u_{2} y_{2 k}+---+u_{s} y_{s k}$ 
Subject to $v_{1} x_{1 j}+v_{2} x_{2 j}+---+v_{m} x_{m j}=1$

$$
\begin{gathered}
u_{1} y_{1 j}+u_{2} y_{2 j}+---+u_{s} y_{s j} \leq v_{1} x_{1 j}+v_{2} x_{2 j}+---+v_{m} x_{m j} \\
u_{1}, u_{2}, u_{3}, \ldots, u_{s} \geq 0, v_{1}, v_{2}, v_{3}, \ldots v_{m} \geq 0
\end{gathered}
$$

Optimal Solution $\left(v^{*}, u^{*}, R^{*}\right)$

The reference set

$$
R_{s}=\left\{j: \sum_{r=1}^{s} u_{r}^{*} y_{r j}=\sum_{i=1}^{m} v_{i}^{*} x_{i j} \quad j=1,2,3, \ldots, n\right\}
$$

The Reference set $R_{s}$ is the Primal Problem. The Primal Problem becomes

$$
\begin{aligned}
& \text { Maximize } R^{*}\left(v^{*}, \mathrm{u}^{*}\right)=\sum_{r=1}^{s} u_{r} y_{r k} \\
& \quad \text { Subject to constraints: } \sum_{r=1}^{s} u_{r}^{*} y_{r j}-\sum_{i=1}^{m} v_{i}^{*} x_{i j} \leq 0 \quad j=1,2,3, \ldots, n \\
& \sum_{i=1}^{m} v_{i} x_{i k}=1 \\
& \text { Non negativity } u_{r} \geq 0, v_{i} \geq 0
\end{aligned}
$$

The above linear programming problem yield the Optimal Solution $\boldsymbol{R}^{*}$, where efficiency score is called Technical Efficiency or CCR Efficiency for the particular $\mathrm{DMU}_{\mathrm{j}}$ and Efficiency scores for all of them are obtained by repeating them for each $\mathrm{DMU}_{\mathrm{j}}, \mathrm{j}=1,2, \ldots \mathrm{n}$. The value of $\boldsymbol{R}^{*}$ is always less than or equal to unity. DMUs for which $R^{*}<1$ are relatively inefficient and those for which $R^{*}=1$ are relatively efficient, having their virtual input-output combination points on the frontier. The frontier itself consists of linear facts spanned by efficient units of the data, and the resulting frontier production function has no unknown parameters. As per the above model we implement empirical model evaluation for the data considered in the next section by explaining the Potential Improvement (P.I) and Reference Comparison (R.C) .

3.2 Potential Improvement: An efficient study not only provides an efficiency score per each unit but also indicates by how much and in which areas an inefficient unit need to improve in order to efficient. This information can enable the targets to be set which could help inefficient units to be improved in their Performance.

3.3 Reference comparison: If the assessment of units was found as inefficient then it is felt to be justified then the information provided can be used as a basis for setting targets for the units. As a first step in setting targets, the inefficient unit should be compared with the units in its reference set.

3.4 Peer Group: Data Envelopment Analysis identifies for each inefficient unit a set of excellent units, called Peer Group, which includes those units that are efficient if evaluated with the optimal weights of inefficient unit. The Peer Group , made up of Decision Making Units which are characterized by operating methods similar to the inefficient unit being examined, which is a realistic term of comparison which unit aim to imitate in order to improve its performance. Another name for the peer group is reference set.

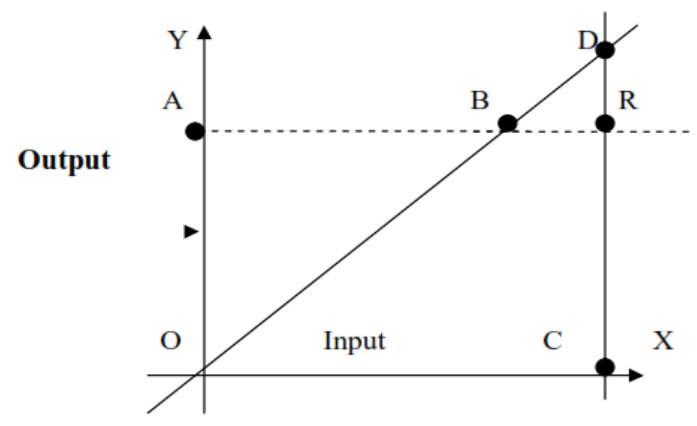

Fig 2 Constant Returns to Scale

From the above figure we understand that, a production of a single output is illustrated graphically. In fig (2) it can be seen that the function $f(x)$, where $f(x)$ is a 
straight line and has a single slope. Hence, for every unit increase in the input that goes into the process, the output produced increases by a constant proportional quantity; hence it represents Constant Returns to Scale (CRS). In this case, $\mathrm{R}$ could be projected onto the frontier either under an input- reducing consideration or an output - increasing consideration. B and D are projected points on the frontier obtained for comparison.

\section{EMPIRICAL STUDY ON DATA SET}

It is well known that every state in India holds a Public Examination at $12^{\text {th }}$ grade. This data was chosen to see the Technical Efficiency/ Peer Performance of the 23 districts of Andhra Pradesh. The Inter Public Examinations data for the academic years 2012-13 and 2013-14 of Andhra Pradesh in the 23 districts were considered the data for Measuring the Technical Efficiency of the Board of
Intermediate Education in Andhra Pradesh district wise. In Inter Public Examinations (IPE), March, 2013, 801419 Regular Candidates have appeared for Examinations. Out of 767208 candidates, 401098 boys and 366110 girls candidates have appeared for Inter Public Examinations and Inter Public Examinations (IPE), March, 2014, 801419 Regular Candidates have appeared for Examinations. Out of 801419 candidates, 413098 boys and 388321 girls candidates have appeared for Inter Public Examinations. In every district, number of boys and girls have appeared for examination and number of boys and girls have passed out in examination date were consider for this analysis. The CCR Model district wise Technical Efficiency (T.E) is presented below.

Table 1 District wise Technical Efficiency for the academic year 2012-13

\begin{tabular}{|c|c|c|c|c|c|}
\hline S. No & District(DMU) & CCR Technical Efficiency $R^{*}$ & References & Peers & Name of the Peers \\
\hline 1 & Adilabad & 0.767 & 0 & 2 & West Godavari, Nellore \\
\hline 2 & Anathapur & 0.837 & 0 & 2 & West Godavari, Nellore \\
\hline 3 & Chitoor & 0.963 & 0 & 2 & West Godavari, Nellore \\
\hline 4 & East Godavari & 0.874 & 0 & 1 & West Godavari \\
\hline 5 & Guntur & 0.906 & 0 & 2 & West Godavari, Nellore \\
\hline 6 & Hyderabad & 0.874 & 0 & 2 & West Godavari, Nellore \\
\hline 7 & Kadapa & 0.821 & 0 & 2 & West Godavari, Nellore \\
\hline 8 & Karim Nagar & 0.766 & 0 & 1 & West Godavari \\
\hline 9 & Khammam & 0.798 & 0 & 2 & West Godavari, Nellore \\
\hline 10 & Krishna & 0.998 & 0 & 2 & West Godavari, Nellore \\
\hline 11 & Kurnool & 0.899 & 0 & 2 & West Godavari, Nellore \\
\hline 12 & Mahaboob Nagar & 0.660 & 0 & 2 & West Godavari, Nellore \\
\hline 13 & Medak & 0.727 & 0 & 2 & West Godavari, Nellore \\
\hline 14 & Nalgonda & 0.709 & 0 & 2 & West Godavari, Nellore \\
\hline 15 & Nellore & 1.000 & 18 & 0 & Nellore \\
\hline 16 & Nizamabad & 0.688 & 0 & 2 & West Godavari, Nellore \\
\hline 17 & Prakasam & 0.935 & 0 & 1 & Ranga Reddy \\
\hline 18 & Ranga Reddy & 1.000 & 2 & 0 & Ranga Reddy \\
\hline 19 & Srikakulam & 0.857 & 0 & 2 & West Godavari, Nellore \\
\hline 20 & Vishakhapatnam & 0.950 & 0 & 2 & West Godavari, Nellore \\
\hline 21 & Vizia Nagaram & 0.668 & 0 & 2 & West Godavari, Nellore \\
\hline 22 & Warangal & 0.704 & 0 & 2 & West Godavari, Nellore \\
\hline 23 & West Godavari & 1.000 & 20 & 0 & West Godavari \\
\hline
\end{tabular}

From the above Table 1 The Technical Efficiency variation for the 23 districts has the following bound $0.660 \leq R^{*} \leq 1.000$. Also three districts have been emerged as efficient namely Nellore, Ranga Reddy, West Godavari and the remaining 20 districts input loses due to CCR Technical efficiency. Potential improvement is required in order to improve in their Performance with regards to results

From the Table 1 it is clear that Nellore, Ranga Reddy, West Godavari are Technically (CCR) Efficient when compared to the 23 districts. It is observed that the Peers to the all other districts seem to be Nellore, Ranga Reddy, West Godavari. West Godavari district is having highest 
references. Peer contribution of this district is more comparable to other districts.

In DEA every technically efficient DMU by its self role model. For Example, Nellore, Ranga Reddy and West Godavari districts are Technically (CCR) Efficient by its self is a role model district. From the above table 1 is noticed that the Technical Efficiency (T.E) of Adilabad district is 0.767. Hence, Adilabad district is technically inefficient. If returns to scale is constant it could have produced its current outputs 0.767 or 76.70 percent of inputs. Thus, removal of all inefficiencies is achieved by reducing all inputs by 0.233 or

Approximately, $23 \%$ of their observed values .In fact, based on the reference set and Peer Weight, we can express the input and output values needed to bring Adilabad district in to efficient status. Similarly we analyse the remaining inefficient district in order to improve their performance to words improve the results.

The distribution of score graph for the academic year 2012-13 is presented below:

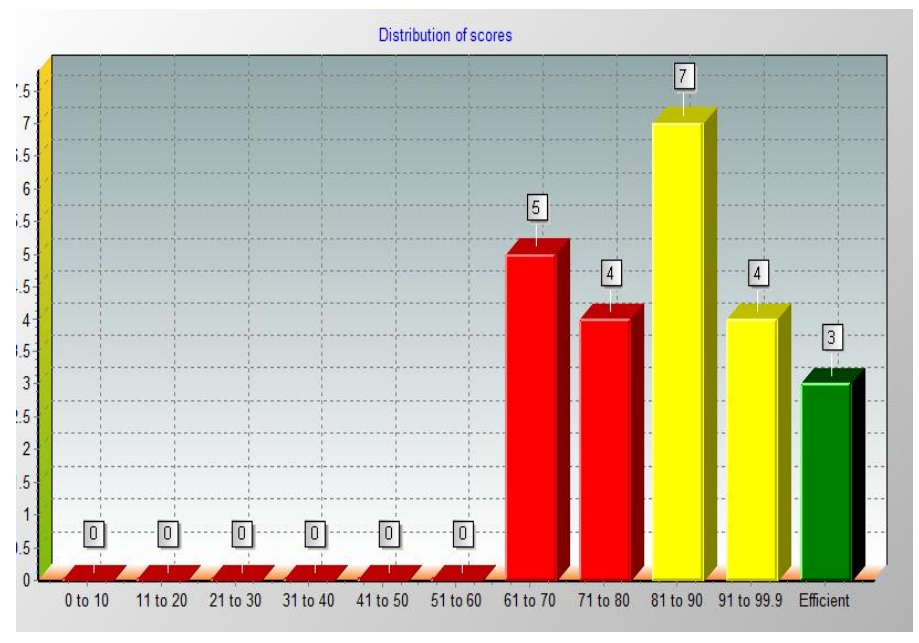

Figure 3 The Distribution of scores graph for the academic year 2012-13

From the above distribution score graph we observed that 6170 score limit 5 districts, 71-80 score limit 4 districts ,81-90 score limit 7 districts ,91-99.9 score limit 4 are technically inefficient Frontier and 3 districts is in efficient status.

The results of Data Envelopment Analysis (DEA) for district wise Technical Efficiency for the academic year 2013-14 is presented below:

Table 2 District wise Technical Efficiency for the academic year 2013-14

\begin{tabular}{|c|c|c|c|c|c|}
\hline $\begin{array}{c}\text { S. } \\
\text { No }\end{array}$ & District(DMU) & $\begin{array}{l}\text { CCR Technical } \\
\text { Efficiency } R^{*}\end{array}$ & References & Peers & Name of the Peers \\
\hline 1 & Adilabad & 0.718 & 0 & 2 & Krishna, West Godavari \\
\hline 2 & Anathapur & 0.852 & 0 & 2 & Krishna, West Godavari \\
\hline 3 & Chitoor & 0.913 & 0 & 2 & Krishna, West Godavari \\
\hline 4 & East Godavari & 0.956 & 0 & 1 & West Godavari \\
\hline 5 & Guntur & 0.912 & 0 & 1 & West Godavari \\
\hline 6 & Hyderabad & 0.923 & 0 & 2 & Krishna, West Godavari \\
\hline 7 & Kadapa & 0.874 & 0 & 2 & Krishna, West Godavari \\
\hline 8 & Karim Nagar & 0.910 & 0 & 1 & West Godavari \\
\hline 9 & Khammam & 0.876 & 0 & 2 & Krishna, West Godavari \\
\hline 10 & Krishna & 1.000 & 22 & 0 & Krishna \\
\hline 11 & Kurnool & 0.861 & 0 & 1 & Krishna \\
\hline 12 & Mahaboob Nagar & 0.686 & 0 & 1 & Krishna \\
\hline 13 & Medak & 0.668 & 0 & 2 & Krishna, West Godavari \\
\hline 14 & Nalgonda & 0.733 & 0 & 2 & Krishna, West Godavari \\
\hline 15 & Nellore & 0.943 & 0 & 1 & Krishna \\
\hline 16 & Nizamabad & 0.760 & 0 & 2 & Krishna, West Godavari \\
\hline 17 & Prakasam & 0.859 & 0 & 1 & Krishna \\
\hline 18 & Ranga Reddy & 0.925 & 0 & 1 & Krishna \\
\hline 19 & Srikakulam & 0.848 & 0 & 2 & Krishna, West Godavari \\
\hline
\end{tabular}




\begin{tabular}{|l|c|c|c|c|c|}
\hline 20 & Vishakhapatnam & 0.964 & 0 & 1 & Krishna \\
\hline 21 & Vizia Nagaram & 0.873 & 0 & 2 & Krishna, West Godavari \\
\hline 22 & Warangal & 0.759 & 0 & 2 & Krishna, West Godavari \\
\hline 23 & West Godavari & 1.000 & 16 & 0 & West Godavari \\
\hline
\end{tabular}

From the above Table 2 The Technical Efficiency variation for the 23 districts has the following bound $0.668 \leq$ $R^{*} \leq 1.000$. Also two districts have been emerged as efficient namely Krishna, West Godavari and the remaining 21 districts input loses due to CCR Technical efficiency. Potential improvement is required in order to improve in their Performance with regards to results in this state.

From the Table 2 it is clear that Krishna and West Godavari are Technically (CCR) Efficient when compared to the 23 districts. It is observed that the Peers to the all other districts seem to be Krishna and West Godavari. Krishna district is having highest references. Peer contribution of this district is more comparable to other districts.

In DEA every efficient DMU by its self role model. For Example, Krishna and West Godavari are Technically (CCR) Efficient by its self is a role model. From the above table is noticed that the Technical Efficiency (T.E) of Mahaboob Nagar district is 0.686. Hence, Mahaboob Nagar district is technically inefficient. If returns to scale is constant it could have produced its current outputs 0.686 or 68.60 percent of inputs. Thus, removal of all inefficiencies is achieved by reducing all inputs by 0.3140 or Approximately,31\% of their observed values .In fact, based on the reference set and Peer Weight, we can express the input and output values needed to bring Mahaboob Nagar district in to efficient status. Similarly we analyse the remaining inefficient district in order to improve their performance to words improve the results.
The Distribution of scores graph for the academic year 2013-2014 is presented below:

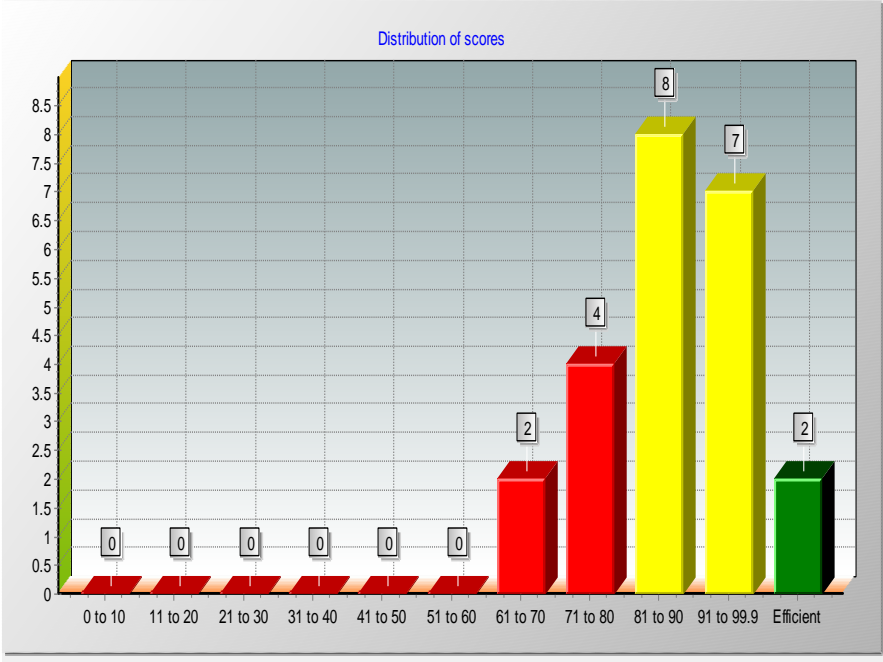

Figure 4 The Distribution of scores graph for the academic year 2013-14

From the above distribution score graph we observed that 61 70 score limit 2 districts, 71-80 score limit 4 districts ,81-90 score limit 8 districts ,91-99.9 score limit 7 are technically inefficient Frontier and 2 districts is in efficient status.

The Summary of Technical Efficiency for the academic year 2012-13 and 2013-14 is presented below for clarity.

Table 3 Summary of CCR Technical Efficiency of Andhra Pradesh

\begin{tabular}{|l|l|l|}
\hline & $2012-13$ & $2013-14$ \\
\hline T.E Mean & 0.844 & 0.861 \\
\hline T.E S.D & 0.116 & 0.097 \\
\hline T.E C.V & $13.74 \%$ & $11.27 \%$ \\
\hline Minimum Technical Efficiency & 0.660 & 0.668 \\
\hline Maximum Technical Efficiency & 1 & 1 \\
\hline No. of Efficient districts & $\begin{array}{l}3 \text { (Nellore, West Godavari, } \\
\text { Ranga Reddy) }\end{array}$ & 2 (Krishna, WestGodavari) \\
\hline Total number of districts & 23 & 23 \\
\hline
\end{tabular}




\section{CONCLUSION}

From this analysis we found that for the academic year 201213 Nellore, West Godavari and Ranga Reddy district performs well as per CCR Technical Efficiency. For the academic year 2013-14 Krishna, West Godavari performs well as per CCR Technical Efficiency. Remaining districts Potential improvement is required for improving in their performance with regards to results. West Godavari district performs well for the both academic years. For the academic year 2012-13 average technical efficiency is 0.844 and 201314 is 0.861 . While compare coefficient of variation c.v of technical efficiency for the academic year 2012-13 and 2013-14, it shows greater consistency between these two years in Andhra Pradesh. If returns to scale is constant in CCR model it could have produced its current outputs percent of inputs. Thus, removal of all inefficiencies is achieved by reducing all inputs of their observed values .In fact, based on the reference set and peer weight, we can express the input and output values needed to bring every DMUs (districts) in to efficient status. For this every district in this state, the educational institutions should focus more on improvement of overall quality of education through continuous improvement programs. If continuous improvement is required any educational institutes. Then only their performance will be in optimal level.

\section{REFERENCES}

[1] Rutter, M. \& Maughan B., “' School effectiveness findings 19702002 ,", Journal of School Psychology ,vol.40, No.6, pp.451475,2002 .

[2] Kwimbere, F.J. , “Measuring efficiency in not-for-profit organizations: an attempt to evaluate efficiency in selected UK university departments". M.Sc. thesis, School of Management, University of Bath,1987.

[3] Johnes, J, "Performance assessment in higher Education in Britain", European Journal of Operational Research vol. 2, pp. $18-33,1996$.

[4] M. Goverdhan, Raju Nellutla, V. V Haragopal, “A Critical Data Envelopment Analysis of Hospital efficiency in India ", , International Journal of Scientific Research, Vol-5,issue2,pp.471475, 2016.

[5] Raju Nellutla, V. V Haragopal , “ Technical efficiency Management wise Schools in Secondary School Examinations of Andhra Pradesh State by CCR Model', IOSR Journal of Mathematics, Vol-13,issue1,pp.1-8,2017.

[6] Raju Nellutla, V. V Haragopal, “ Performance of Management Schools in Secondary School Examinations of Andhra Pradesh State by Data Envelopment Analysis', International Journal of Scientific Research, Vol-4,issue9,pp.179-182,2015.

[7] Pina ,V., Y Torres, L., “'Analyse through DEA Teaching activity of the Account Department', in Spanish Public University,1995.
[8] Subramanyam, T., and C.S Reddy, "Measuring the Risk Efficient in Indian Commercial Banking -DEA approach" , East West Journal of Economics and Business, Vol XI(1\&2) 76-105,2008.

[9] Raju Nellutla, V. V. Haragopal, "Data Envelopment Analysis of SSC Public Examinations 2009 -2011 of Andhra Pradesh", , Global Journal for Research Analysis, vol -4,issue 7,pp.141144,2015 .

[10] Banker, R.D., R.F. Charnes, \& W.W. Cooper, '“Some Models for Estimating Technical and Scale Inefficiencies in Data Envelopment Analysis', Management Science vol. 30, pp. 10781092, 1984.

[11] Charnes, A , W. Cooper, \&E., Rhodes , "Measuring the Efficiency of decision making units", European Journal of Operational Research vol. 2, pp. 429-444,1978.

\section{AUTHORS PROFILE}

Dr. Raju Nellutla, working as Associate Professor of Mathematics/ Statistics and Department Coordinator in Department of Humanities and Sciences, Guru Nanak Institutions Technical Campus, Hyderabad, Telangana, India, Obtained his Master degree in M. Sc (Applied Statistics) from University

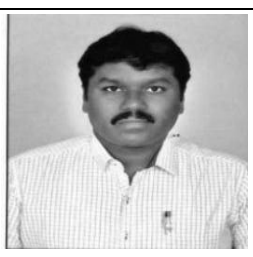
College of Science, Osmania University, Hyderabad. He did his Ph. $\mathrm{D}$ in Statistics from Kakatiya University, Warangal, Telangana. His area of research includes Statistics, Advanced Operations Research and Data Envelopment Analysis. He has published 8 research papers in reputed international journals. Dr. Raju Nellutla is sessional member of ISCA. He has 15 years of teaching experience.

Dr. M. Goverdhan, working as Assistant Professor of Statistics in Department of Humanities and Sciences, CVR College of Engineering, Hyderabad, Telangana, India, Obtained his Master degree in M. Sc (Applied Statistics), M.Phil.( Statistics), Osmania University, Hyderabad. He did his $\mathrm{Ph} . \mathrm{D}$ in Statistics from Kakatiya University, Warangal, Telangana. He has 15 years teaching experience.

Dr. V. V Haragopal was a former Professor of Statistics, Head and Chainman Board of Statistics and Director CQM at Osmania University, Hyderabad. He has guided around $20 \mathrm{Ph} . \mathrm{D}$ and $7 \quad$ M. Phil students and published more than 100 papers in reputed international and national journals. He has

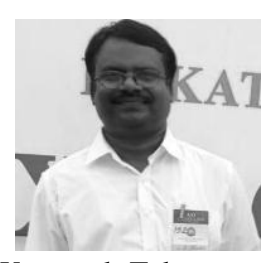
delivered many invited talk across the India. Presently working as Professor of Mathematics in Birla Institute of Technology and Science, Pilani, Hyderabad Campus, Hyderabad. 